\title{
Tespiti Güç Bir İmza Sahteciliği Yöntemi "Serbest Taklit”: Bir Olgu Sunumu
}

\section{A Hard-to-Detect Signature Forgery Method "Freehand Simulation": Case Report}

\author{
Güven Seçkin Kırcl ${ }^{1}$, Halil İlhan Aydoğdu ${ }^{1}$, Hasan Okumuşs ${ }^{1}$, Erdal Özer ${ }^{1,2}$ \\ Ahmet Eryılmaz $\dot{I}_{\text {ssmail Birincioğlu }}^{3}$ \\ ${ }^{I}$ Karadeniz Teknik Üniversitesi Tıp Fakültesi Adli Tıp Anabilim Dalı, Trabzon \\ ${ }^{2}$ Karadeniz Teknik Üniversitesi Adli Bilimler Enstitüsü, Trabzon \\ ${ }^{3}$ Balıkesir Üniversitesi Tıp Fakültesi Adli Tıp Anabilim Dalı, Balıkesir \\ ${ }^{4}$ Okmeydanı Eğitim ve Araştırma Hastanesi, İstanbul
}

\begin{abstract}
Özet
İmza; atan kişiyi kesin bir şekilde belirleyen ve atıldığı belgeyi onaylama iradesini belirten, kişiye ait el yazısı yanında her çeşit işarete verilen isim olarak tanımlanmaktadır. Kişinin kendisi tarafindan atılmayan yani kendi eli ürünü olmayan sahte imzalar çeşitli yöntemler kullanılarak elde edilmektedirler. Bunlar, üstten kopyalama, bakarak taklit, serbest taklit yöntemi ile atılan imzalar, üzerinde imza ihtiva eden pulların sökülerek başka belgelere nakli, bilgisayar ve fotokopi teknolojileriyle atılan imzalar ve hayali kişiler adına atılmış uydurma imzalar olarak sıralanabilmektedir. Buna son zamanlarda icat edilerek giderek artan sıklıkla karşılaştı̆̆ımız imza makineleriyle atılanlar eklenebilir. Sıraladığımız bu yöntemler içerisinde "Serbest Taklit Yöntemi" ile yapılan imza sahteciliği belirli yönleriyle diğer yöntemlerden ayrılmaktadır. Serbest Taklit Yöntemi ile atılan imzalarda sahteci, günlerce atacağı imzaya özen içinde çalışıp denemeler yaparak, imzayı tüm yönleriyle hafizasına alır ve taklidini oluşturabileceğine kanaat getirdiğinde bir bütün olarak atar. Sahtecinin birçok kez deneme yapma şansı olması nedeniyle de orjinale oldukça benzeyen, tespiti güç bir imza modeli ortaya çıkması hiç te uzak bir ihtimal değildir. Bu nedenlerden ötürü, farkl1lıklar detaylarda gizli kalabilmektedir. Birçok özelliğiyle bu yöntem, incelemeciler açısından ortaya çıkarılması en güç olan sahtecilik tipidir.

Olgumuza konu olan inceleme konusu imzaya ve karşılaştırma imzalarına baktığımızda, hız, işleklik, istif, eğim, kalem bası dereceleri de dahil olmak üzere birçok tanı unsuru yönünden birbirine benzer özellikler içerdiklerini görmekteyiz. Ancak imzalar daha ayrıntılı incelendiğinde; özellikle başlangıç ve bitiş noktalarında, ara grama yapıları ve sayılarında, imzaların dikey olarak yukarı doğru çıkan ve aşağı doğru inen gramalarında, kement ve kıvrımlarında ciddi farkl1lıklar olduğu anlaşılmaktadır. Bu yönleriyle değerlendirildiğinde olgumuzun konusu olan imzaların, serbest taklit yöntemiyle atılmış oldukları kanaatine varılmıştır.

$\mathrm{Bu}$ çalışmada tespiti nispeten güç olan bir imza sahteciliği olgusunun örnek görüntülerle sunulması ve bu konuda dikkatli olunması gerekliliğine ve deneyimli uzman görüşü alınmasının önemine vurgu yapılması amaçlanmıştır.
\end{abstract}

Anahtar Kelimeler: Serbest Taklit; İmza Sahteciliŭi; Adli Belge.
Sorumlu Yazar: Güven Seçkin Kırcı

Karadeniz Teknik Üniversitesi Tip Fakültesi

Adli Tip Anabilim Dal, Trabzon

E-mail: guvenseco@hotmail.com

Geliş: 09.05.2016 Düzeltme: 14.06.2016 Kabul: 15.06.2016

\begin{abstract}
Signature is defined as any kind of distinctive mark which assures the identity of its generator in a certain way while demonstrating the generator's will for approval of the content of the document to which it is subscribed, not limited to those generated with a person's handwriting, Forged signatures, that is, the signatures not generated by its owner himself on the related document, can be produced by various methods. Those methods can be listed as tracing, freehand simulation using a model, freehand simulation from memory, revenue stamp transferring, photocopying or computer assisted reproduction techniques and fabricating on behalf of imaginary identities. Generation via signature machines, a recently invented way gradually becoming more frequent, can be added to this list. Freehand simulation from memory is distinguished from other afore-mentioned methods in certain aspects. Simulator studies the genuine signature carefully for days, learns its all features by heart, make trials of generation and finally executes the simulation in one move when convinced for success. This method is the hardest to reveal for examiners with its distinct features.

In our case, the signature subject to forgery investigation and the signatures obtained for comparison were found to be similar in signature characteristics such as signature velocity, dysfluency (jerk), slant and pen pressure. With a more detailed examination, it is understood that signatures are far different regarding start and stop points, stroke settings and counts, upstroke and down stroke patterns. Considering those findings, it is inferred that signature subject to investigation is generated by simulation using freehand method by memory.

In this study, a forgery case relatively hard to detect is presented with sample images with the aim to emphasize acting in a very sensitive manner and asking for experienced specialist view for such cases is a must.
\end{abstract}

Keywords: Freehand Simulation; Signature Forgery; Questioned Document.

\section{Giriş}

İmza, atan kişiyi kesin bir şekilde belirleyen ve atıldığı belgeyi onaylama iradesini belirten, kişiye ait el yazısı yanında her çeşit işarete verilen isim olarak tanımlanmaktadır (1,2). 2525 sayılı "Soyadı Kanunu'nun" 2. 
Maddesinde "imzada öz ad önde, soyadı sonda kullanılır" ibaresi yer almaktadır $(2,3)$. Ancak incelemelerde karşımıza çeşitli şekillerde atılmış imzalar sıklıkla çıkmaktadır. Bunlar, içeriğinde hem gramalar hem de işaretler içeren karmaşık tersimde imzalar olabileceği gibi, yalnızca anlamsız şekiller ve işaretlerden oluşan basit tersimli imzalar da olabilmektedir (4). İmzalarda kişiye, ortama, yaşa, kültüre, ırka, sağlık durumuna göre birçok noktada değişkenlik olmakla birlikte elde yeterli mukayese örnekler olduğu takdirde orijin kimlik tespitini yapmak mümkün olmaktadır (5). Bazı ulusal yayınlarda her ne kadar imzaların yazı unsuru ile atılan ve yazı unsuru içermeyen olarak iki temel karakterde atıldığı belirtilmekle beraber, uluslararası yayınlarda imzalar yapısal olarak 3 temel tipte sinıflandırılmaktadırlar. Bunlar;

1. Text-based (Tamamı yazı unsurundan oluşmuştur ve her bir harf açık şekilde anlaşılabilir).

2. Mixed (Hem yazı unsuru hem de grama-çizgilerden oluşmaktadır).

3. Stylized (Sadece çizgilerden oluşmaktadır) (6).

Ülkemizdeki imza tiplerini araştıran çalışmalara baktığımızda, yalnızca çizgilerden oluşan imzaların çok daha sıklıkla kullanıldığı görülmektedir. Oysaki yurtdışı kaynaklarda bu durumun tersine şekilde test-based, mixed tipin daha yaygın olduğunu göstermektedir. Bu nedenle yalnızca çizgilerden oluşan imzaların aidiyetini tespit etmek zaman zaman çok zor olabilmektedir (7).

Sahtecilik ya da sahtekârlık kavramı geniş anlamda "işlenmesi için bir hileye, bir yalana başvurulan bütün suçlar" olarak tanımlanmaktadır $(8,9)$. Çoğunlukla yazarlar bu düşünce ile sahtekârllğ̣ "sözde, yazıda ve fiilde" olmak üzere üçe ayırmışlardır (9). Kişinin kendisi (atfedilen) tarafindan atılmayan yani kendi eli ürünü olmayan (sahte) imzalar çeşitli yöntemler kullanılarak yapılabilmektedir. Bunlar, üstten kopyalama, bakarak taklit, serbest taklit, üzerinde imza içeren pulların nakli, bilgisayar ve fotokopi teknolojileriyle atılan imzalar ve hayali kişiler adına atılmış uydurma imzalar olarak sıralanabilmektedir (10). Buna son zamanlarda giderek artan sıklıkla karşılaştığımız imza makineleriyle atılanlar eklenebilmektedir (11).

Sıraladığımız bu yöntemler içerisinde "Serbest Taklit Yöntemi” ile atılan imzalar belirli yönleriyle diğer yöntemlerden ayrılmaktadır. Serbest Taklit Yöntemi ile atılan imzalarda sahteci günlerce atacağı imzaya özen içinde çalışı denemeler yaparak, imzayı tüm yönleriyle hafızasına alır ve taklidini oluşturabileceğine kanaat getirdiğinde model imzaya bakmadan bir bütün olarak atar (8,10,12-15). Söz konusu sahteciliğin başarılı olabilmesinde etken olan faktörler arasında; taklit edilen imzanın basit yapı arz et- mesi, taklit edenin yeteneği ve taklit eden kişinin tecrübesi ve konuyla ilgili yoğun çalışma ortaya koyması bulunmaktadır $(4,13)$. Birçok özelliğiyle bu yöntem hem sahteciler açısından yapılması hem de incelemeciler açısından ortaya çıkarılması en güç olan imza sahtecilik tipidir $(8,15,16)$. Bu yöntem ile atılan imzalar oldukça seri, hızlı ve akışkandır. Bu imzalar orijinal imza hızına eşit, yakın hatta daha hızlı olabilmektedir $(8,13,16,17)$. Sahtecinin elinin imza sahibinden daha işlek ve hızlı olması durumunda gerçek imzada bulunan bozuk harf ve grama şekilleri sahteci tarafindan daha düzgün ve düzenli olarak oluşturulur (15). Serbest taklit ile yapılmış imzalarda dikkat edilmesi gereken husus, sahtecinin el hareketinin basitlik ve işlekliğidir. Örneğin el hareketi gerçek imzada bulunan kement, kıvrım gibi özelliklerin uzun çalışmalar sonucunda bile oluşturulması neredeyse imkânsızdır (15). Diğer yöntemlerde izlenen titreklikler, tereddütler, kalem kaldırma ve mürekkep birikimleri gibi arızaları sıklıkla içermezlerken, orijinal imzadan kaligrafik açıdan farklılıklar içermeleri dikkat çekicidir $(10,15,16,18)$. Bu imzalar sahtecinin kendi başına oluşturacağı tümden sahte belgelerde de kullanılabilmekle birlikte çoğunlukla üçüncü şahısların (noter ya da diğer resmi memurlar, veznedar gibi) önünde atılan imzalar için söz konusu olmaktadır (4).

Çalışmamızda tespiti nispeten güç olan bir sahtecilik olgusunun örnek görüntülerle sunulması ve bu konuda çok dikkatli olunması ve gerektiğinde deneyimli uzman görüşü alınması gerekliliğinin vurgulanması amaçlanmıştır.

\section{Olgu}

Cumhuriyet Başsavcılığı tarafindan yürütülmekte olan bir davada, davacı tarafin ifadesinde; 01.09.2010 tarihinde bir telefon ve internet hizmeti veren kuruluş tarafindan belli bir telefon ve hizmet numarası ile hizmet aldığı ve hizmetin bedelini ödemediği için şirket tarafından icra yoluyla tahsilat yapılmaya çalışıldığını öğrendiği, bunun üzerine ilgilinin müşteri müdürlüğüne giderek durumu araştırdığı, bu sırada telefon hattının başka bir firma üzerine kayıtlı olduğunu öğrendiği, bu araştırma ve inceleme sırasında hattın açılması için düzenlenen evraklarda bulunan imzanın kendine ait olmadığını gördüğü, kendi imzasına benzer şekilde taklit edilmiş imzalar olduğunu fark ettiğini ve bu durumla ilgili savcılık üzerinden itiraz gerçekleştirdiği kayıtlıdır.

Cumhuriyet Savcıllığına yapılan bu itiraz üzerine, ilgili dosya imzanın aidiyeti açısından bilirkişiye gönderilmiştir. Uzman bilirkişi raporunda; incelenmesi istenilen sözleşmede davacı adına atfen atılı imza ve karşılaştırma imzalarındaki çizgi ve gramaların tek tek özellikleri ve birbirleriyle olan ilişkileri, kâğıdın kullanımı, kişisel 
alışkanlıklar, istif, eğim, doğrultu, tersim biçimi, hız, alışkanlıklar ve bası dereceleri gibi yönlerden karşılaştırmalar yapıp, dikey ve yatay kuvvetli 1şıklar altında, çeşitli büyütme özelliklerinde mercekler kullanılarak yapılan değerlendirmelere göre inceleme konusu sözleşme ve eklerinde davacı adına atfen atılı imzalar ile davacının karşılaştırma imzaları arasında gerek şeklen ve gerekse yukarıda sayılan diğer özellikler yönünden belirgin farklılıklar saptandığından söz konusu imzaların mevcut olan karşılaştırma imzalarına kıyasla davacının eli ürünü olmadığı serbest taklit yöntemiyle atılmış imzalar olduğu kanaatine vardı̆̆ kayıtlıdır.
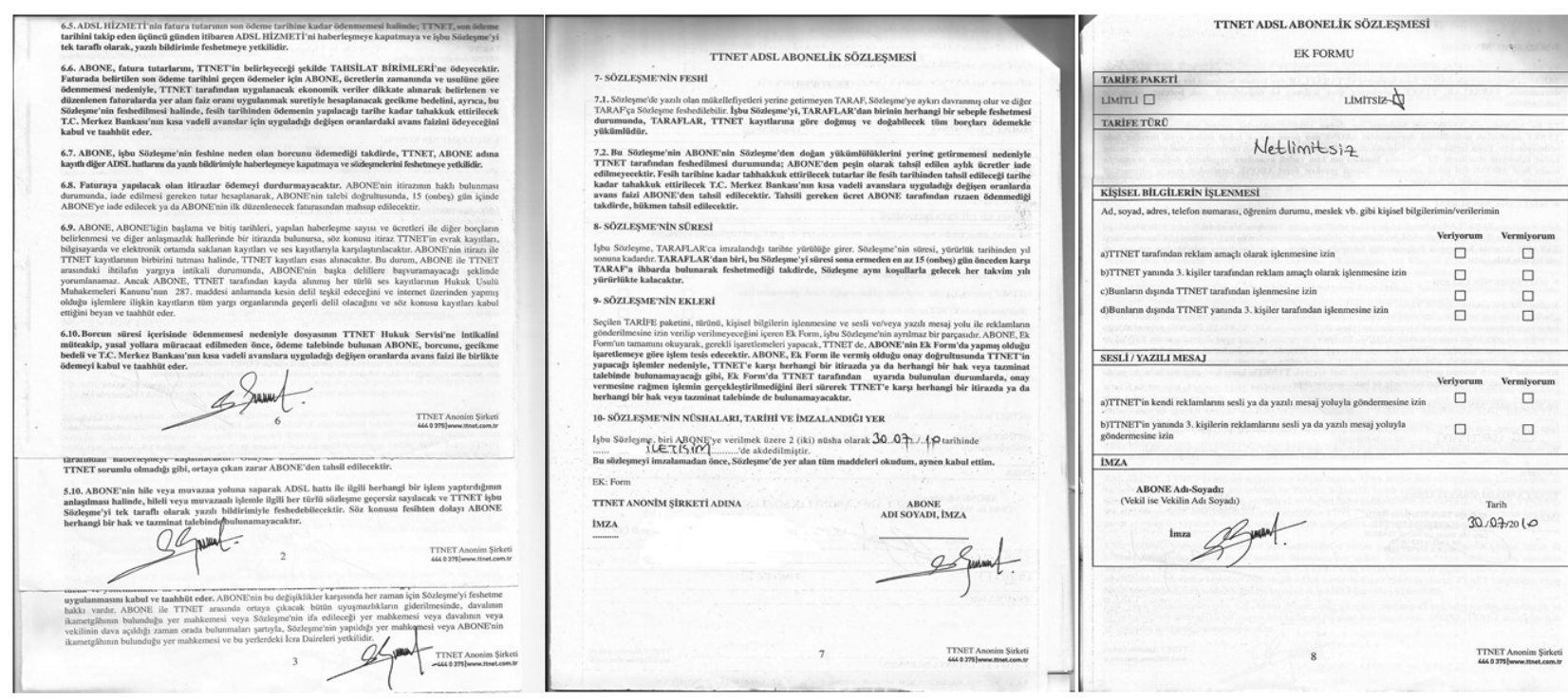

Resim 1. İnceleme konusu belgeler
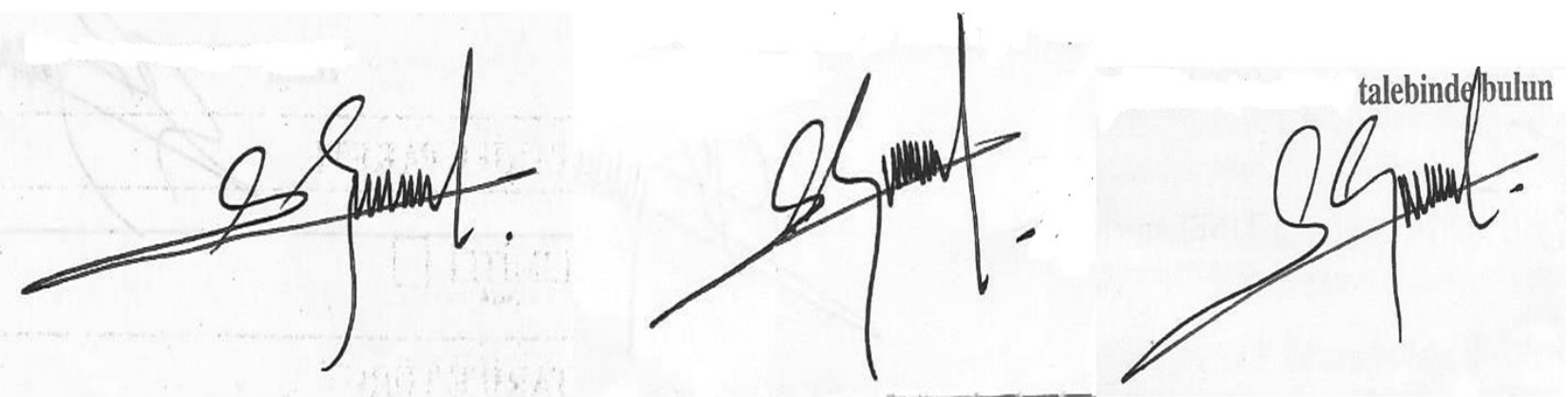

Resim 2. Şahsa ait olduğu iddia edilen inceleme konusu imza örneği
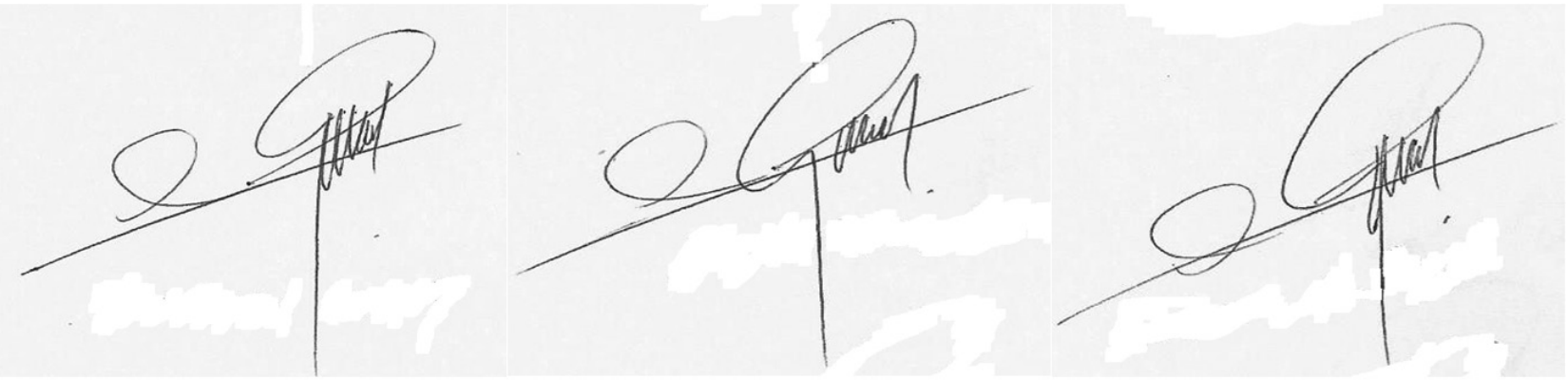

Resim 3. Şahsa ait olduğu kabul edilen karşılaştırma imza örneği 


\section{Tartışma}

İmza, üzerinde bulunduğu belgeyi, atan kişi tarafından kesin olarak tasdik eden ve tüm dünyada en yaygın kullanılan yöntem olarak karşımıza çıkmaktadır. Bu nedenle imza sahteciliği yazının var olduğu tarihten günümüze dek süregelen ve yine en yaygın görülen sahtecilik tiplerinden biridir. Birçok araştırmanın, yazının, romanın ve filmin konusu olmuştur (19).

Bir imzanın attı̆̆ iddia edilen kişiye olan aidiyetinin, başka bir söyleyişle o kişinin eli ürünü olup olmadığının belirlenmesinde, imzanın tersim tarzı, eğimi, doğrultusu, hızı, işlekliği, istifi, kalem bası derecesi, kişinin alışkanlıkları gibi birçok tanı unsurunun incelenmesi yanında bu konuda yardımcı birçok teknolojik cihaz da bulunmaktadır (4). Bu yöntemlerin yardımıyla imzaların aidiyeti çoğu kez tespit edilebilmekte olsa da bazı durumlarda tespiti mümkün olmayan veya çok zor tespit edilebilecek imzalara da rastlanmaktadır. Gerek sahteciliğe yönelik düşünülen yeni yöntemler gerekse bu amaçlı hazırlanan ıslak imza makineleri gibi teknolojik icatlar günümüzde adli belge ve imza incelemecilerinin işini giderek zorlaştırmaktadır (9). Bu sebeplerden ötürü adli belge inceleme uzmanlarının hem niteliklerinin hem de sayılarının arttırılması bir zorunluluktur.

İmza sahtecilikleri arasında sayılan birçok yöntem içinde "Serbest Taklit Yöntemi" ile atılan imzalar belirli yönleriyle diğer yöntemlerden ayrılmaktadır. Serbest Taklit Yöntemi ile atılan imzalarda sahteci günlerce atacağı imzaya özen içinde çalışıp denemeler yaparak, imzayı tüm yönleriyle hafızasına alır ve taklidini oluşturabileceğine kanaat getirdiğinde bir bütün olarak gerçek imzalara bakmadan atarlar. Birçok özelliğiyle bu yöntem, incelemeciler açısından ortaya çıkarılması en güç olan sahtecilik tipidir. Bu yöntem ile atılan imzalar oldukça seri, hızlı ve akışkandır. Diğer bazı imza sahteciliklerinde sıklıkla görülen titreklikler, tereddütler, kalem kaldırma ve mürekkep birikimleri gibi arızaları içermezlerken, orijinal imzadan kaligrafik açıdan farklılıklar içermeleri en dikkat çekici yanlarıdır. Orijinal imzalarla olan farklar ancak küçük detaylardadır (10).

Olgumuza konu olan ve Resim-2 de gösterilen inceleme konusu imzaya ve Resim-3 de gösterilen karşılaştırma imzasına baktığımızda, iki imzanın birçok tanı unsuru yönünden birbirine benzer özellikler içerdiğini görmekteyiz. Tersimi birbirine oldukça benzer izlenen iki imzanın da birbirine yakın eğimde ve yakın hız işleklikte imzalar oldukları, sahte imzada olmasını beklediğimiz titreklikler, tereddütler ve kalem kaldırmaya bağlı mürekkep bırakma arazlarının olmadığını görmekteyiz.
Ancak iki imza daha ayrıntılı incelendiğinde; özellikle imzaların başlangıç ve bitiş noktalarında, ara grama yapıları ve sayılarında, imzaların çıkan ve inen çizgilerinde farklılıklar olduğu anlaşılmaktadır. Bu yönleriyle değerlendirildiğinde Olgumuzun konusu olan imzaların serbest taklit yöntemiyle atılmış oldukları görülmektedir.

Tüm dünyada her alanda bilirkişiler zaman zaman hatalı sonuçlara ulaşabilmektedir. Bu bağlamda adli belge inceleme uzmanlarının da hata yapması mümkündür. Serbest taklit yöntemi ile yapılan imza sahtecilikleri de bu anlamda sahte imzayı atan kişi için yapması en zor ve aynı zamanda incelemeciler için de tespit edilmesi en güç olan sahtecilik tipidir. Bu nedenle bu tip sahteciliğin tespiti için farklı zaman dilimlerinde atılmış çok sayıda mukayese belgenin temin edilmesi, konuyla ilgilenen incelemecilerin bu konuda yeterli tecrübe ve bilgi birikimine sahip olmaları gerekmektedir. Aksi halde istenmeyen kötü sonuçlar kaçınılmazdır, yapılan her hata adaletin zamanında ve doğru tesis edilmesine engel olacaktır.

\section{Kaynaklar}

1. Türk Dil Kurumu Türkçe Sözlük, Ankara, 1988.

2. Akın SG. Adli Grafolojide Sağlıklı Mukayese Belge Temininin Esasları, İstanbul Üniversitesi Adli Tip Enstitüsü Sosyal Bilimler Anabilim Dalı Yüksek Lisans Tezi, İstanbul 2001, s: 21,

3. Soyadı Kanunu, Kanun No: 2525, RG: Tarih: 2/7/1934 Say1 : 2741. http://www.mevzuat.gov.tr/MevzuatMetin/1.3.2525. pdf (Erişim tarihi 08.03.2016).

4. Bafra J. İmza Yazı ve Adli Belge İncelemeleri. 1. Bask1, Ufuk Matbaası, İstanbul, 2006, s. 73.

5. Birincioğlu İ, Alkan N, Kurtaş Ö ve ark. Serbest taklit yöntemiyle oluşturulmuş bir imza sahteciliği: olgu sunumu. Y1llık Adli Tip Toplantıları 2001 Kitabı. İstanbul, 2001.

6. Baysan GY. Dreyfus Davası: Gerçek ve Adalet Savaşçısı Zola, Hacettepe Üni Edebiyat Fak Dergisi. 2002; 19(1); 181-195.

7. Mohammed L, Found B, Rogers D. Frequency of Signature Styles in San Diego County. J Am Society Questioned Document Examiners. 2008; 11(1);12-14.

8. İplikçi Ş. El Yazıları ve İmzaların Kriminal Yönden İncelenmesi. 1. Bask1, Marki Ofset, İstanbul, 2011, s. 29-100.

9. Birincioğlu İ, Özkara E. Adli Belge İncelemelerinde Bilinmeyenler, Örneklerle Yazı ve İmza Analizi ile Islak İmza Kavram1. Türkiye Barolar Birliği Dergisi. 2010;87;403-33.

10. Aşıcıoğlu F (Editör), Adli Belge İncelemesi. 1. Baskı, Beta Basım A.Ş. İstanbul, 2005, s. 31-33, 61.

11. Taşdemir K. Belgelerde Sahtecilik Suçları. 1. Baskı, Ertem Basım Ltd. Şti, Ankara, 2013, s. 18-9.

12. Hilton O. Scientific Examination of Questioned Documents. USA, CRC Press LLC, 1993:183-6.

13. Aşıcıoğlu F. (Editör), Adli Bilimlerde El Yazısı ve İmza İncelemeleri, Öner Matbaac1lı, İstanbul, 2007, s. 151-3. 
14. Levinson J. Questioned Documents A Lawyer's Handbook, Academic Press, Londra, 2001, s. 49.

15. Kurtaş Ö. Adli Tıp Açısından Grafolojinin Önemi. Adalet Bakanlığı Adli Tıp Kurumu Başkanlığı Uzmanlık Tezi, İstanbul 1992, s. 77.

16. Kandemir K. İstemli Olarak Değiştirilen İmzalardaki Kalıcı Unsurlar. İ.Ü. Adli Tıp Enstitüsü Yüksek Lisans Tezi, İstanbul 2001, s.1.
17. Slyter SA. Forensic Signature Examination. Charles C Thomas Publisher, Springfield, Illinois, USA. 1995, s. 36-7.

18. Ellen D. The Scientific Examination of Documents Methods and Techniques. Second Edition, Taylor-Francis Ltd, Londra, 1997, s. 35.

19. Asicioglu F, Turan N. Handwriting changes under the effect of alcohol. Forensic Sci Int. 2003; 132(3): 201-210. http:// dx.doi.org/10.1016/S0379-0738(03)00020-3 